\title{
A Critique of Mcdowell's Demonstrative Thought in the Cognitive Process of Perception
}

\author{
Emmanuel Ola Akintona \\ Department of Communication and General Studies, College of Agricultural Management and Rural \\ Development, University of Agriculture, Abeokuta, Nigeria \\ Email: emmakintona@yahoo.com
}

Received 12 June 2014; revised 16 July 2014; accepted 28 July 2014

Copyright (C) 2014 by author and Scientific Research Publishing Inc.

This work is licensed under the Creative Commons Attribution International License (CC BY). http://creativecommons.org/licenses/by/4.0/

(c) (i) Open Access

\begin{abstract}
The recent trend in epistemology is the consideration about the possibility of non-conceptual content in the cognitive process of perception. This has ever been generating serious polemics among philosophers of perception on the true nature and character of the content of our perceptual experience at perception. Two groups eventually emerged: the non-conceptualists and the conceptualists. The non-conceptualists on one hand advocate that mental representations of the world do not necessarily presuppose concepts by means of which the content of these representations can be specified, hence, cognizers can have mental representation of the world that are non-conceptual. They argue that creatures without conceptual capacity can be in a content-bearing state even though they lack concept, memory or linguistic ability. The conceptualists on the other hand claim that non-conceptual content neither exists nor is representationally significant to perception because they are mere qualitative content of sensation i.e. purely sensory content. For them, cognizers can only have mental representations of the world if they possess adequate concepts by means of which they can specify what they represent else their experience is unavoidable conceptual. John McDowell (1994), a leading conceptualist, therefore introduced the concept "demonstrative thought" to counter non-conceptuality. For him, no perceptual experience is indescribable or indemonstrable: a demonstrative concept like "that shade" is also a demonstrable concept. This paper adopts the philosophical conceptual analytic tool to argue that the introduction of demonstrative concepts by McDowell does not in any way hinder the possibility of non-conceptual content in perception.
\end{abstract}

\section{Keywords}

Perception, Cognition, Conceptual Experience, Non-Conceptual Experience and Demonstrative Thought 


\section{Introduction}

The conceptualists and the non-conceptualists portray different views on the state, nature and character of the content of perceptual experience while the conceptualists say it is concept bound, the non-conceptualists say, it is without concept. Non-conceptualism, on one hand, is the view that mental representations of the world do not necessarily presuppose concepts by means of which the content of these representations can be specified, thus, cognizers can have mental representation of the world that are non-conceptual. They argue that aside human beings creatures without conceptual capacity can also be in a content-bearing state (state of non-conceptuality) even though they lack concept, memory or linguistic ability. Concepts, for this group, mean intentionally complete truth-evaluable contents of judgment and belief. Therefore, any content of experience devoid of intentionally complete truth-evaluable contents of judgment and belief is non-conceptual. Conceptualism, on the other hand, is the view that non-conceptual content of perceptual experience neither exists nor is representationally significant to perception. For this view, what the non-conceptualists refer to as non-conceptual content is nothing but a mere qualitative content of sensation i.e. pure sensory content. Hence, cognizers can only have mental representations of the world if they possess adequate concepts by means of which they can specify what they represent. John McDowell (1994), D. W. Hamlyn (1994) and Bill Brewer (2004) are among the strong advocates of this claim. For them, perceptual experience cannot but be conceptually structured on the occasion of perceiving. Perception for them is always in a kind of relational position with the perceiver i.e. in form of propositional attitudes like thoughts, beliefs and judgments. They contend that in such manner concepts are spontaneously derived in perception and dependent on experience; hence perceptual experience cannot but be concept-bound. McDowell, the champion and the leading advocate of conceptualism, argues that there is no perceptual experience which will be so indescribable, at least, that the perceiver cannot demonstrate with such concepts like "that shade". He contends that any perceptual experience that is demonstrable or describable is conceptual. But, are all experiences describable or demonstrable? How will McDowell react to and conceive the content of the experience of a non-physicist who observes and points to a nuclear energy only by saying "that shade"? Would it mean that the non-physicist had the concept of the nuclear energy? This paper argues that the introduction of demonstrative concepts by McDowell does not in any way hinder the possibility of non-conceptual content in perception, instead, it further strengthen and justify the non-conceptual position.

\section{What Is Non-Conceptual Content?}

Gareth Evans in his famous book The Varieties of Reference (1982) was first to raise the question of the possibility of a non-conceptual content in perception in the contemporary times, and ever since there had being serious polemics among philosophers of perception as to what is the true nature and character of the content of perceptual experience. Two groups eventually emerged from this position: one group, the non-conceptualists, at one end of the extreme, is of the view that mental representations of the world do not necessarily presuppose concepts by means of which the content of these representations can be specified. The other group, the conceptualists, claim that non-conceptual content neither exists nor is representationally significant to perception because they are mere qualitative content of sensation i.e. purely sensory content. Evans argues that perceptual experience involves some non-conceptual content. He contended that there are some cognitive contents that are not fully determined by conceptual capacities, and that such cognitive contents that outstrip conceptual capacities possessed by rational and non-rational animals can best be described non-conceptual. Hence, he made a distinction between informational state and judgment. According to this distinction, experience can be separated from judgment and belief. Evans (1982: p. 122) states:

When a person receives something, he receives (or, better, gathers) information about the world $\cdots$ People are, in short and among other things, gatherers, transmitters and storers of information. These platitudes locate perception, communication, and memory in a system (informational system), which constitutes the substratum of our lives.

The above quotation shows that our contact with the world only provides us with information that conglomerates into concepts, memory and cognition. So, if informational state of one's perceptual experience is independent of belief and judgment, then there is room for a non-conceptual content in perception. He argues that experience is always more fine-grained than what concept we formed about it. For example, one sees more shades of colour than one can name. Evans (1982: p. 229) postulates, “we do not have as many colour concepts as there 
are shades of colours as we can perceptually discriminate, so that the contents of perception must be more finegrained than the concepts we possess". He also argues that experiences are belief-independent (Evans, 1982: p. 123). In this case, it is possible for someone to continue to undergo an illusion even if he is aware that it does not correctly represent reality. So, there is every reason for one not to believe what he sees, because the senses could be deceptive.

Corroborating Evans view, particularly, on experience being belief-independent and non-conceptual, Tim Crane (1988) puts forward some arguments to support the thesis on account of some unusual experiences such as that of the waterfall illusion. This illusion is explained in terms of the after-image of a waterfall that is projected onto a stationary object which produces the contradictory appearances of something moving and yet remaining still. The point Crane seems to be making here is that in an ordinary case of conceptual content, there cannot be contradictory instances of such content. So, in this case, experience must be non-conceptual at the instance of perception. Susan L. Hurley (1998) also proves non-conceptuality of experience from the linguistic perspective. She sees perception as something which is strictly attached to linguistic achievement, which implies that any creature that lacks linguistic capacity cannot conceptualize the world. She posits, "Concept is strictly tied to linguistic achievement", and that "non-humans and human infants, even though enjoy perceptual experience, have no capacity for concept formation” (Hurley, 1998: p. 136).

\section{What Is Demonstrative Thought?}

Demonstrative thought is a perceptual concept developed by McDowell to contend the possibility of non-conceptual content in perception. He conceives it as the most atomic form of human perceptual experience. Such a thought, according to him, is really a demonstrable one because it is able to refer to or distinguish a feature of perceptual experience. For example, when a perceiver utters "that shade" and pointing out an aspect of his perceptual experience, such a perceptual-demonstrative thought, according to the conceptualists, cannot be nonconceptual because it is demonstrable and thus necessarily conceptual. McDowell believes that such demonstrative thought already presupposes that the perceiver possess some general concepts like "shade" and "that", to be able to achieve such a recognition of his experience. Given this analysis, nobody would be able to appreciate their perceptual states or have any true knowledge of "that shade" in their representational content unless they possess such general concepts. McDowell's contention is that it is hopeless trying to classify that aspect of perceptual experience as non-conceptual since it is demonstrable in thought. Whatever is demonstrable in thought, he says, is necessarily conceptual since such experiences already have some concepts, like "that shade".

McDowell (1994: pp. 56-57) claims that the pairing of the capacity for demonstrative thought with the possession of general concepts for the features presented in experience that provides one with all the conceptual resources required to capture the rich details of one's experience. He takes the case of colour experience to elucidate his position:

It is possible to acquire the concept of a shade of colour, and most of us have done so $\cdots$ in the throes of an experience of the kind that putatively transcends one's conceptual powers-an experience that ex hypothesi affords a suitable sample-one can give linguistic expression to a concept that is exactly as fine-grained as the experience, by uttering a phrase like "that shade", in which the demonstrative exploits the presence of the sample.

Consequently, he contends that when attending to the features presented in my visual experience of the wall before me which looks, say, red, but for which I have no concept red, I can still conceptually express the finedgrained nature of my colour experience by saying or thinking "the wall of my office is that shade of red". Such ways of picking out the wide varieties of features presented in our colour experiences, according to McDowell, are always available to us and this suffice for a conceptual representation of the detail of our colour experience. He also claims that the demonstrative abilities is a genuine conceptual capacities shared by all experiencing creatures, and they will have to be shown to actually play a role in the determination of the content of experience.

McDowell (1994: p. 63) describes all forms of experiences as necessarily conceptual and argues that if a nonconceptual content of experience cannot help in fixing beliefs and judgments, then, it is irrelevant. All experiences are embedded with beliefs and judgments and are better understood in the sense of an accumulated knowledge; beliefs and judgments, that is, they are instantaneously derived from perception. But, we know that 
sometimes our beliefs are not only different from our experience, given the experience of an illusion; we even misjudge some of those experiences. So, if we want to strictly attach beliefs and judgments to experience, the result would only deny some of our normal experiences.

\section{A Critical Evaluation of Demonstrative Thought}

The non-conceptualists contend that in spite of our conceptual capacity and its gradual development, we are still left with a whole realm of non-conceptuality which deserves theoretical recognition. This left-over McDowell necessarily accept granting a theoretical recognition ${ }^{1}$ but contended that such theoretical recognition of the non-conceptual experience is of limited function hence it is absolutely irrelevant to the cognitive process. He therefore introduced the concept of demonstrative thought "that shade" to nullify the granted non-conceptuality as relevant aspect of cognition.

However, the adoption of "that shade" as a demonstrative concept by McDowell does not confirm that the perceiver actually have the concept of the shade in question, even though, the perceiver recognizes it some instances of perception. "That shade" is a mere proto-concepts used to describe a state of affairs that one actually lack understanding and proper concepts for. McDowell argues that for the perceiver to point at a shade of colour on the wall as "that shade" is enough to claim the possession of the concept of that colour. This cannot be true. If having concepts require that the subject have adequate knowledge about the experience, then, McDowell's argument fails. A mere pointing at a shade as "that shade" as a point of recognition is inadequate for having the concept. We are of the opinion that McDowell's argument about demonstrative concepts still does not offer us any genuine reason to suppose that it indeed has a role to play in determining the conceptual status of the perceiver's experience. The fact that we can conceptually represent in thought a demonstration, particularly with the fine-grained example, does not guarantee that its representational content is itself conceptual. McDowell (1994: p. 57) argues for the authenticity of demonstrative concepts this way:

In the presence of the original sample, "that shade" can give expression to a concept of a shade $\cdots$ What is in play here is recognitional capacity, possibly quite short-lived, that set in with the experience. It is in the conceptual content of such a recognitional capacity that can be made explicit with the help of a sample, something that is guaranteed to be available at the time of the experience with which the capacity set in.

Even with his assertion here, the argument is still not strong enough to establish that the perceiver has the concept required for knowing the object perceived.

We observe again that the possession of a particular demonstrative concept deployed at an instance of an experience, which extends beyond one's conceptual resources, does not appear to be antecedent to the experience itself. Instead, it seems that the ability to form the demonstrative concept in question depends on having already a suitable sample in experience. Without the experience, it seems that the demonstrative concept would not have been available. If this is so, we do not see how the demonstrative concept, which McDowell emphasizes, would play any significant role in determining the conceptual status of the experience. The fact that concepts, which correspond to the features presented in one's experience, is at play does not suffice that one could not have had the particular experience he had if he did not possess those concepts. This also has not shown that experience has conceptual content.

If what the conceptualists mean by experience being conceptually derived is that it will definitely fall into a kind of category in the mind, we may concede their argument; but if it is that the perceiver already possesses the concepts, in terms of having the knowledge or understanding the experience, we think they are wrong. Nobody acquires knowledge or understanding of an experience instantly as McDowell wants us to believe with regard to demonstrative concepts, since we are not talking about intuition here. Knowledge is acquired gradually and is thus developmental in nature; it is not spontaneously derived from experience just as concepts are also not. Concepts acquisition develops over time; it becomes clearer and clearer to the subject as he develops and matures with experience.

Truly, the capacity for demonstrative thought gives a subject the conceptual resources required to reflect upon features of his experience for which he otherwise lacks concepts initially, but that is not what McDowell's con-

\footnotetext{
${ }^{1}$ John McDowell accepted this fact as acknowledged by Bob Brandom in his article "No Experience Necessary: Empiricism, Non-inferential knowledge, and Secondary Qualities” http://www.nyu.edu/gsas/dept/philo/courses/representation/papers/BrandomNEN.pdf 2000 (accessed June 2012).
} 
ceptualists' account of the content of experience requires. His account of demonstrative concepts seems perfectly consistent with the content being conceptual in all ramifications, which means that the subject can claim knowledge about the experience. His description is comparatively similar to that put forth by Gareth Evans, which grounds judgments based on perceptual experience whereby we move from a state with non-conceptual content to a state of conceptual content (McDowell, 1994: p. 49). So, McDowell cannot be right about the perceived achievement of demonstrative concepts.

Experiences seem to have their representational content independent of a subject's possession of demonstrative concepts, and the demonstratives simply provide a means of embracing in thought and at varying degrees of determinateness, the features presented in one's experience. At most, what McDowell's discussion of demonstrative concepts establishes is that the features of a subject's experience could always be matched by some protoconcepts or pre-logical concepts possessed by the subject, but this also does not show that for an experience to have the content it requires, the subject will possess a particular (demonstrative) concept, which is what any conceptualists' account would require.

The introduction of demonstrative thought by McDowell obstructs what should have been a straightforward compromise between the conceptualists and the non-conceptualists. The implication is that if arguments could show that these concepts do not really serve the purpose intended for them, then the differences are dissolved. The question is, therefore, pertinent: Does the perceptual demonstrativeness of an experience really presupposed conceptual ability and precluded non-conceptuality? Or does the ability to demonstrably recognize a feature of one's perceptual experience denotes the knowledge of that experience? I doubt if this is correct because the fact that the perceiver can demonstrate his experience as "that shade" does not say that he has an appropriate concept for it. If the perceiver actually has the required concepts to capture the detailed experience, he would not be demonstrating it. Often times, what one lacks the appropriate concepts or vocabulary for is demonstrated so as convince others of his/her idea about the experience. The example of a non-physicist that saw a nuclear energy, lacks the appropriate vocabulary cum concepts to describe it may struggle to demonstrate what he is seeing as it appears in his non-conceptual cognition while a physicist having listened to his description may now understand his demonstration as a nuclear energy. In fact, there are so many of such experiences as human beings encounter the world. Think of the first experience of Adam (the first creature according to the scriptures) with the Sun, the Moon and the Stars; he will definitely perceive these objects but may lack the necessary conceptual capacities for them than to describe them. It seems to me that the introduction of the demonstrative thought itself rather shoots the conceptualists in the leg than defending it because one only struggle to demonstrate what one lacks appropriate concepts for. "That shade" only signifies the least logical and linguistic conceptual apparatus left for the perceiver to describe his experience and this further justifies his non-conceptuality of the experience.

John McDowell also defends the demonstrative concept using the Wittgenstein's case of the person who says "I know how tall I am, putting his hand on top of his head to prove it"2. But the person in Wittgenstein's example does not, by saying or thinking "this tall," come to know of a height in metres or in any other units which is what knowing how tall one is requires on the usual understanding. It is not even clear that such a person thereby comes to know how tall he is in the sense that he could indicate which of the markings on a wall on the opposite side of the room is roughly his height. By contrast, a perceptual demonstrative thought latches on to a magnitude, shade or colour, only if that magnitude, shade or colour, is itself given in the experience which makes the perceptual demonstrative concept available. There is the possibility of making perceptual demonstrative reference to a magnitude shade or colour, and not knowing what magnitude shade or colour it is one is thinking about. That such a perceptual demonstrative reference is the most fundamental means of knowing what magnitude, shade or colour is, is really in doubt.

Again, not all rationally mature human beings can make distinctions between variations in colours and shades, some people do not have a robust concept of a shade of a colour. Not even all experiencing creatures share general concepts as McDowell opines and if this is so, then, it will be wrong to suppose that two subjects' experiences must differ at the finest-grained level because they do not share the same concepts. Any representational differences, which might arise at the conceptual level, should be attributed only to differences in the cognitive resources available to each of them and not to how their experiences represent the world. Their ability to exercise different but overlapping concepts in attending to the details of their experience seems to be "grounded in their experiencing the same shade in the same way” (Wright, 2003: p. 8).

\footnotetext{
${ }^{2}$ John McDowell's reference is to Wittgenstein's (1993) Philosophical Investigations, section 279.
} 
The fleeting nature of demonstrative thought is another challenge it has to defend. McDowell himself points out that one of the conditions necessary for possessing a genuine conceptual capacity is for "the very same capacity to embrace a colour in mind can persist beyond the duration of the experience itself $\cdots$ if only for a short time (McDowell, 1994: p. 57). This means that the capacity to identify something, as an instance of a particular feature, by means of a demonstrative expression cannot be isolated from the experience in which the demonstration is first exercised. McDowell admits that the capacity for recognition in terms of "that shade" in the above example can endure only for a "short time" and that is what we count as a sufficient duration of a recognitional capacity. But, we need to note that if the capacity on which McDowell wants us to rely disappears immediately after the removal of the original sample, then there will be no reason to think that utterances or thought of "that shade" will have the sort of conceptual content which he insists they do. If the capacities fail to last at least long enough to facilitate identification of other samples as exemplifying the feature in question, then we cannot take McDowell's account very seriously.

It would seem, however, that McDowell's account of demonstrative concepts cannot endure for long after the removal of the original sample. Not long enough, that is, to suppose that the recognitional capacity is at work. In fact, the marked brevity of the normal duration of the capacities makes it seem inappropriate to think of them as being in any way recognitional. Recognition, in the sense McDowell employs it, is a product of a mere chance and that may not justify having the concept truly. For example, if the subject is faced with two cans, which contain paints of similar but not identical shades, it is doubtful that the demonstrative abilities of which McDowell speaks would be of any use in determining which is the correct to purchase. But, perhaps after the appropriate training, one could acquire the ability to differentiate between certain shades without a sample being present. But, that is of no help to McDowell, for we continue to have experiences with determinate features even in the absence of such training.

It is important in McDowell's view that the conceptual content of the sort "the wall is that shade" in thoughts and utterances be recognitional to the subject's capacities at all times, else, it cannot be considered conceptual. If the ability of the subject to employ the demonstrative "that shade" to pick out a shade, such as red, for which he has no matching concept is to count as a genuine conception of that shade, then it cannot be said to provide the basis for the much needed figure in a conceptual account of the content of experience. This will simply mean that the subject has a concept which refers to red but not any real concept of red. Thus he would not have at his disposal matching concepts for all of the features of his experience which runs contrary to the conceptualists' thesis. Then, we can say that the capacities appealed to by McDowell are not conceptual, not in the sense that they contain no proto-conceptual content at all for the use of "that shade", but, that the conceptual capacities at work in such usage are not of the recognitional sort required by a conceptualists' account.

\section{Conclusion}

McDowell's introduction of demonstrative thought into the cognitive process of perception does not in any way confirm that the perceiver actually has the concept of the perceived object, it only establishes that he is seeing something. The perceptual demonstrativeness of an experience does not really presuppose conceptual ability hence it cannot be said to really serve the purpose for which it is intended. If the ability to demonstrably recognize a feature of one's perceptual experience does not denote having the knowledge of that experience, then, we can say that the capacities appealed to by McDowell are not conceptual, not in the sense that they contain no proto-conceptual content at all for the use of "that shade", but, that the conceptual capacities at work in such usage are not of the recognitional sort required by a conceptualists' account. At best, what McDowell's demonstrative concepts establish is that the features of a subject's experience could always be matched by some protoconcepts or pre-logical concepts possessed by the subject, but this also does not show that the experience is conceptual, at least, to the extent that the subject could claim knowledge about, which is what any conceptualists' account would require. Drawing a line of demarcation between conceptual and non-conceptual concepts in human cognitive process of perception, and affirming the possibility of non-conceptual content in the process of perception, goes a long way to significantly help modern researchers to know that not all that are perceived or experienced are immediately conceptualized and described appropriately. Knowledge evolved gradually in its dynamism, and as human develops so his understanding about his experience develops. Hardly can we find any scientific theory that withstands the test of time without some flexibility or variations. The best ever achieved in any scientific research work is a probable-knowledge which is less than certainty (it may be $99.9 \%$ but cannot be $100 \%$ certain). Knowledge is dynamic and developmental in nature. 


\section{References}

Evans, G. (1982). The Varieties of Reference. Oxford: Clarendon Press.

Brewer, B. (2004). Perception and Conceptual Content. In E. Sosa, \& M. Steup (Eds.), Contemporary Debates in Epistemology (pp. 89-112). Oxford: Basil Blackwell.

Crane, T. (1988). The Waterfall Illusion. Analysis, 48, 142-147. http://dx.doi.org/10.1093/analys/48.3.142

Hamlyn, D. W. (1994). Perception, Sensation and Non-Conceptual Content. The Philosophical Quarterly, 44, 139-153.

Hurley, S. L. (1998). Consciousness in Action. Cambridge, MA: Harvard University Press.

McDowell, J. (1994). Mind and World. Cambridge, MA: Harvard University Press.

Wittgenstein, L. (1993). Philosophical Occasions, 1912-1951. In J. Klagge, \& A. Nordmann (Eds.), Philosophy. Indianapolis, IN: Hackett.

Wright, W. T. (2003). Projectivist Representational and Colour. Philosophical Psychology, 41. 
Scientific Research Publishing (SCIRP) is one of the largest Open Access journal publishers. It is currently publishing more than 200 open access, online, peer-reviewed journals covering a wide range of academic disciplines. SCIRP serves the worldwide academic communities and contributes to the progress and application of science with its publication.

Other selected journals from SCIRP are listed as below. Submit your manuscript to us via either submit@scirp.org or Online Submission Portal.
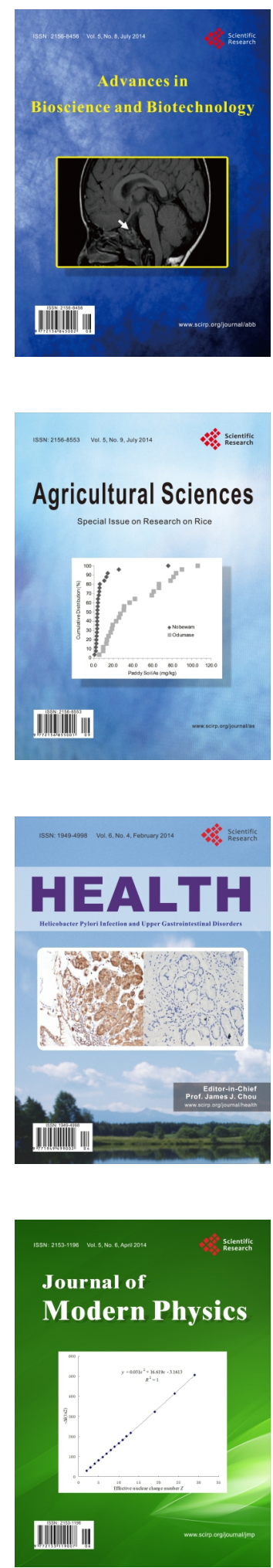
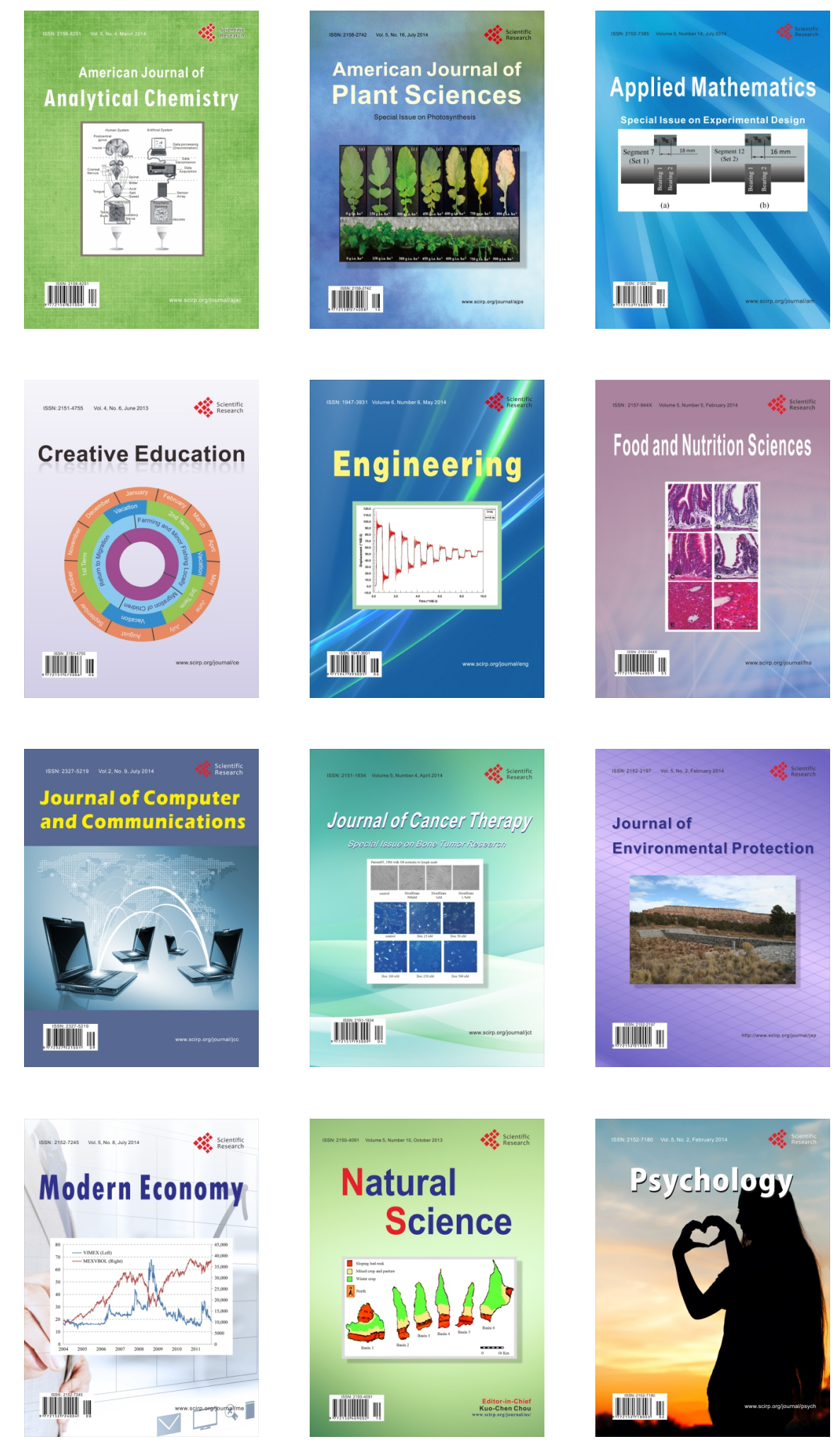